\title{
Concentração foliar de manganês e zinco em laranjeiras adubadas com óxidos e carbonatos via foliar ${ }^{1}$
}

\author{
Leaf concentrations of manganese and zinc in the orange fertilized via foliar \\ application with oxides and carbonates
}

\author{
Leandro José Grava de Godoy ${ }^{2 *}$, Roberto Lyra Villas Bôas ${ }^{3}$, Rodrigo Seigi Yanagiwara ${ }^{4}$, Clarice Backes $^{5}$ e \\ Claudinei Paulo de Lima ${ }^{6}$
}

\begin{abstract}
RESUMO - Dentre os micronutrientes, o Zn e o Mn limitam a produção dos citros, no Brasil. A aplicação foliar tem sido a forma tradicional de fornecimento, contudo, a eficiência desta adubação depende de uma série de fatores, entre eles o tipo de fertilizante. Foram realizados dois experimentos em pomar com laranjeiras Pêra, enxertadas em limão cravo, com sete anos de idade, em Botucatu, SP. No primeiro experimento foram avaliadas três fontes de Mn via foliar: carbonato de manganês A, carbonato de manganês B e sulfato manganoso, em duas doses para cada fertilizante, correspondente a 250 e $500 \mathrm{~g} \mathrm{ha}^{-1}$ de $\mathrm{Mn}$, mais o controle, pulverizado somente com água. No segundo experimento foram testadas três fontes de Zn para aplicação foliar: óxido de zinco A, óxido de zinco B e sulfato de zinco, em duas doses para cada fertilizante, correspondente a 375 e $750 \mathrm{~g} \mathrm{ha}^{-1}$ de $\mathrm{Zn}$, mais o controle. As amostragens de folhas foram realizadas mensalmente, iniciando aos 30 dias após aplicação dos tratamentos. A aplicação foliar com carbonato de manganês $\mathrm{B}$, na dose de $500 \mathrm{~g} \mathrm{ha}^{-1} \mathrm{Mn}$, e com óxido de zinco $\mathrm{B}$, na dose de $750 \mathrm{~g} \mathrm{ha}^{-1}$, proporcionaram, respectivamente, níveis nutricionais adequados de Mn e Zn nas folhas de laranjeira. Na ausência de chuvas, os teores adequados de Mn e Zn no solo, não permitem suprir satisfatoriamente as laranjeiras Pêra enxertadas em limoeiro cravo.
\end{abstract}

Palavras-chave: Citrus sinensis L.. Adubação Foliar. Micronutrientes. Laranja.

\begin{abstract}
Among micronutrients, $\mathrm{Zn}$ and $\mathrm{Mn}$ limit the production of citrus in Brazil. Foliar application has been the traditional form of supply, however the efficiency of this type of fertilization depends on a number of factors, including the type of fertilizer used. Two experiments were conducted in an orchard of seven year old Pêra orange, grafted onto Rangpur lime, in Botucatu, São Paulo. In the first experiment three sources of Mn, applied via foliar application, were evaluated: manganese carbonate A, manganese carbonate B and manganese sulphate, at two rates per fertilizer, corresponding to 250 and and $500 \mathrm{~g} \mathrm{ha}^{-1}$ of $\mathrm{Mn}$, plus a control sprayed with water only. In the second experiment three sources of $\mathrm{Zn}$ were tested for foliar application: zinc oxide A, zinc oxide B and zinc sulphate at two rates per fertilizer, corresponding to 375 and $750 \mathrm{~g} \mathrm{ha}^{-1}$ of $\mathrm{Zn}$, plus the control. Samples of leaves were collected monthly, beginning 30 days after application of the treatments. The foliar application of manganese carbonate B at a rate of $500 \mathrm{~g} \mathrm{ha}^{-1} \mathrm{Mn}$, and zinc oxide $\mathrm{B}$ at a rate of $750 \mathrm{~g} \mathrm{ha}^{-1}$, each provided adequate nutritional levels of $\mathrm{Mn}$ and $\mathrm{Zn}$ in the leaves of the orange. With the absence of rain, the appropriate levels of $\mathrm{Mn}$ and $\mathrm{Zn}$ in the soil are not enough to supply the Pêra orange grafted onto Rangpur lime.
\end{abstract}

Key words: Citrus sinensis L.. Foliar fertilization. Micronutrients. Orange.

\footnotetext{
*Autor para correspondência

${ }^{1}$ Recebido para publicação em 04/11/2010; aprovado em 03/03/2013

Trabalho realizado com recursos do Departamento de Solos e Recursos Ambientais, Faculdade de Ciências Agronômicas, UNESP, Botucatu-SP

${ }^{2}$ Campus Experimental de Registro, Universidade Estadual Paulista "Júlio de Mesquita Filho", Registro-SP, Brasil, legodoy@ @egistro.unesp.br

${ }^{3}$ Departamento de Solos e Recursos Ambientais, Faculdade de Ciências Agronômicas/UNESP, Botucatu-SP, Brasil, rlvboas@ fca.unesp.br

${ }^{4}$ Faculdade de Ciências Agronômicas/UNESP, Botucatu-SP, Brasil, rsyanagiwara@ @ca.unesp.br

${ }^{5}$ Universidade Estadual de Goiás/UnU de São Luis de Montes Belos, São Luis de Montes Belos-GO, Brasil, claricebackes@yahoo.com.br

${ }^{6}$ Faculdades Integradas de Ourinhos e Faculdade/FIO e Faculdade de Tecnologia de Ourinhos/FATEC, Ourinho-SP, Brasil, neiagro@ yahoo.com.br
} 


\section{INTRODUÇÃO}

A safra brasileira de laranja atingiu 19,48 milhões de toneladas (477,4 milhões de caixas) em 2012, em uma área de 846,8 mil hectares, sendo o Brasil o maior produtor mundial, responsável por mais de $28,4 \%$ do total de laranjas produzido no mundo (IBGE, 2013; FAOSTAT, 2013).

As plantas cítricas são exigentes em zinco ( $\mathrm{Zn})$, manganês $(\mathrm{Mn})$, boro (B) e ferro $(\mathrm{Fe})$ e a deficiência desses é comum na citricultura mundial, limitando a produtividade e a qualidade dos frutos no Brasil (QUAGGIO et al., 2003). A adubação (via solo e foliar), responsável por cerca de $17 \%$ do orçamento total da atividade rural citrícola, tem sido considerada fundamental para atingir alta produtividade e consequente maximização dos lucros (GHILARDI et al., 2001). Miranda et al. (2010) ressaltam que para algumas condições, como por exemplo, no caso de micronutrientes, a aplicação via foliar, durante o ciclo em que foi detectada a deficiência, pode mitigar efeito negativo na produtividade. $\mathrm{Na}$ citricultura, existem pesquisas que demonstram a eficiência da aplicação foliar do Zn, Mn, B e Fe (SANTOS et al., 1999, TARIQ et al., 2007, PAPADAKIS et al., 2007, SARTORI et al., 2008a, YASEEN; AHMAD, 2010), porém é necessário aplicá-los a cada fluxo de vegetação nova, já que os nutrientes aplicados na vegetação anterior não se redistribuem para os tecidos novos (SARTORI et al., 2008b, BOARETTO et al., 2002).

$\mathrm{O}$ efeito da adubação foliar depende da velocidade de absorção do nutriente pelas folhas e de sua translocação na planta (BOARETTO et al., 2003). A velocidade de absorção dos nutrientes, por sua vez, é dependente da fonte empregada e da quantidade aplicada. Alcarde e Vale (2003) citam que no Brasil existem fontes de micronutrientes solúveis em água, como os quelatos, nitratos, sulfatos e cloretos, e insolúveis em água, como os carbonatos, fosfatos, óxidos, fritas, dentre outras. Para que estas fontes insolúveis em água possam ser utilizadas na adubação foliar é necessário que o tamanho das partículas seja menor que o tamanho do estômato da cultura alvo da aplicação (FERREIRA, 2009). Com esta redução de tamanho das partículas pode-se obter vantagens, tais como: alta dispersibilidade em calda, rápida utilização do ativo pela planta e ausência de problemas na aplicação (entupimento de bicos de pulverização), melhorar a operação de transporte, devido à alta concentração de ativos e a baixa reatividade auxilia a compatibilidade com defensivos, quando em caldas. Entretanto, há escassez de conhecimento sobre produtos mais adequados para adubação foliar (ROSSI et al., 2004), assim como as doses e métodos mais adequados para aplicação de produtos, como os óxidos e carbonatos.
A eficiência da adubação foliar pode ser avaliada por diferentes métodos, sendo o mais comum, e prático, o método indireto, no qual se realiza a pulverização de nutrientes sobre as folhas e, decorridos 20 a 60 dias para a absorção dos mesmos, quantifica-se a alteração da composição química da planta (BOARETTO et al., 2003). As concentrações foliares representam o estado nutricional das plantas, identificam deficiências e/ou excessos e avaliam a necessidade de ajustar as adubações (RUSCHEL et al., 2004).

As adubações foliares com Zn e Mn em laranjeira podem nutrir as plantas, entretanto a quantidade de nutriente absorvida dependerá de uma série de fatores entre elas o tipo de fonte. $\mathrm{O}$ uso de fontes não solúveis em água podem proporcionar um efeito mais prolongado na absorção dos nutrientes, sendo suficiente uma única aplicação, além de não ter problemas de causar queima do tecido foliar e permitir a mistura com outras fontes.

Objetivou-se com os experimentos avaliar a concentração foliar de Zn e Mn em laranjeiras, em função do tempo após a aplicação e do tipo de fertilizante foliar.

\section{MATERIAL E MÉTODOS}

Foram conduzidos dois experimentos, de setembro de 2004 a fevereiro de 2005, em pomar uniforme de laranjeiras Pêra enxertadas em limão cravo, com sete anos de idade, no espaçamento de $7 \times 4 \mathrm{~m}$, localizados na Fazenda Três Irmãos, em Botucatu, SP, situada a $22^{\circ} 52^{\prime} 25,0^{\prime \prime} \mathrm{S}$ e $48^{\circ} 37^{\prime} 50,3$ ' O a 844 metros de altitude. De acordo com a temperatura e precipitação pluviométrica, classifica-se o clima da região como sendo do tipo Cwa, segundo a classificação climática de Köepen, caracterizado pelo clima tropical de altitude, com inverno seco e verão quente. A precipitação pluviométrica média anual é de $1.445 \mathrm{~mm}$, sendo que as chuvas tendem a concentrar-se nos meses de novembro a abril. Apresenta temperatura média anual de $21,0^{\circ} \mathrm{C}$ e evapotranspiração de $700 \mathrm{~mm}$. O solo do local é Neossolo Quartzarênico textura arenosa ( $890 \mathrm{~g} \mathrm{~kg}^{-1}$ areia; $40 \mathrm{~g} \mathrm{~kg}^{-1}$ silte e $70 \mathrm{~g} \mathrm{~kg}^{-1}$ argila), classificado de acordo com critérios da Embrapa (1999).

No primeiro experimento foram testadas três fontes de $\mathrm{Mn}$ via foliar: carbonato de manganês $\mathrm{A}$ (500 $\mathrm{g} \mathrm{dm}^{-3} \mathrm{Mn}$ ou $284 \mathrm{~g} \mathrm{~kg}^{-1} ; \mathrm{d}=1,76 \mathrm{~g} \mathrm{dm}^{-3} ; \mathrm{pH}$ $=8,5 ; 90 \%$ das partículas menor que $4,8 \mu \mathrm{m}$ e $50 \%$ menor que $1,8 \mu \mathrm{m})$; carbonato de manganês $\mathrm{B}\left(500 \mathrm{~g} \mathrm{dm}^{-3}\right.$ Mn ou $274 \mathrm{~g} \mathrm{~kg}^{-1} ; \mathrm{d}=1,827 \mathrm{~g} \mathrm{dm}^{-3} ; \mathrm{pH}=8,0$ e $100 \%$ das partículas menor que $10 \mu \mathrm{m} ; 69 \mathrm{~g} \mathrm{~L}^{-1} \mathrm{~N}$, na forma de ureia), ambos em formulação suspensão concentrada, com o nutriente insolúvel em água, e sulfato manganoso $\left(\mathrm{MnSO}_{4} .3 \mathrm{H}_{2} \mathrm{O}-310 \mathrm{~g} \mathrm{~kg}^{-1} \mathrm{Mn}\right)$, 
em pó, solúvel em água, em duas doses para cada fertilizante, correspondente a 250 e $500 \mathrm{~g} \mathrm{ha}^{-1} \mathrm{Mn}$, totalizando sete tratamentos, incluindo o controle, pulverizado com água, com nenhum adubo foliar.

No segundo experimento foram testadas três fontes de $\mathrm{Zn}$ via foliar: óxido de zinco A $\left(750 \mathrm{~g} \mathrm{dm}^{-3}\right.$ $\mathrm{Zn}$ ou $441 \mathrm{~g} \mathrm{~kg}^{-1} ; \mathrm{d}=1,76 \mathrm{~g} \mathrm{dm}^{-3} ; \mathrm{pH}=9,2 ; 90 \%$ das partículas menor que $1,8 \mu \mathrm{m}$ e $50 \%$ menor que $0,8 \mu \mathrm{m}$ ); óxido de zinco B $\left(700 \mathrm{~g} \mathrm{dm}^{-3} \mathrm{de} \mathrm{Zn}\right.$ ou $400 \mathrm{~g} \mathrm{~kg}^{-1}$; $\mathrm{d}$ $=1,734 \mathrm{~g} \mathrm{dm}^{-3} ; \mathrm{pH}=9,0 ; 100 \%$ das partículas menor que $10 \mu \mathrm{m} ; 18 \mathrm{~g} \mathrm{~L}^{-1} \mathrm{~N}$, na forma de ureia), ambos em formulação suspensão concentrada, com o nutriente insolúvel em água, e sulfato de zinco $\left(\mathrm{ZnSO}_{4} 7 \mathrm{H}_{2} \mathrm{O}\right.$ - $210 \mathrm{~g} \mathrm{~kg}^{-1} \mathrm{Zn}$ ), em pó, solúvel em água, em duas doses para cada fertilizante, correspondente a 375 e $750 \mathrm{~g} \mathrm{ha}^{-1}$ $\mathrm{Zn}$, mais o controle, pulverizado somente com água.

Os tratamentos foram dispostos no delineamento inteiramente casualizado com quatro repetições. A unidade experimental foi composta por cinco plantas, considerando as três centrais como úteis, deixando uma linha de cada lado como bordadura.

A aplicação foi realizada com pulverizador tratorizado com capacidade para 400 Le provido de pistola com vazão de 4,0 $\mathrm{L} \mathrm{min}^{-1}$ e bico cônico cheio $\mathrm{n}^{\circ}$. 5, até o molhamento total das folhas, em uma única aplicação. $\mathrm{O}$ solo abaixo da copa das plantas pulverizadas foi coberto com saco plástico durante a aplicação para evitar que a solução aplicada atingisse este. Como foi verificado que praticamente não houve escorrimento da calda este foi retirado logo após a aplicação. Antes e no decorrer das aplicações foram realizadas medições de temperatura (média de $22,9^{\circ} \mathrm{C}$ ), umidade relativa do ar (média de 52,6\%) e velocidade do vento (média de $4,8 \mathrm{~km} \mathrm{~h}^{-1}$ ), para se evitar valores impróprios para aplicação. $\mathrm{O}$ volume da calda foi de, aproximadamente, $3,8 \mathrm{~L}_{\text {planta }}{ }^{-1}$ e a concentração da solução utilizada foi de 0,18 e $0,37 \mathrm{~g} \mathrm{~L}^{-1}$ para as doses de 250 e $500 \mathrm{~g} \mathrm{ha}^{-1}$ das fontes de Mn e de 0,27 e $0,55 \mathrm{~g} \mathrm{~L}^{-1}$ para as doses de 375 e $750 \mathrm{~g} \mathrm{ha}^{-1}$ das fontes de $\mathrm{Zn}$.

As amostragens de folhas iniciaram-se em setembro, antes

da aplicação dos tratamentos, coletando uma amostra geral para a área experimental e depois, realizadas mensalmente, coletando-se a terceira ou quarta folha de ramos vegetativos no início de florescimento, dos quatro quadrantes e localizados na região mediana da planta, totalizando 12 folhas por planta e três plantas por repetição (36 folhas por repetição). As folhas coletadas foram lavadas, acondicionadas em sacos de papel e secas em estufa de circulação de ar forçada por 72 horas na temperatura de $65{ }^{\circ} \mathrm{C}$. Após a secagem, as lâminas foliares foram moídas e enviadas ao laboratório para determinação de macro e micronutrientes, de acordo com Malavolta et al. (1997).

Entre a segunda e a terceira análise (novembro e dezembro) foi aplicado, por planta, $1,0 \mathrm{~kg}$ de calcário dolomítico e, duas semanas após, $1,0 \mathrm{~kg}$ do fertilizante misto 20-05-20, conforme o resultado da análise de solo, na camada de 0 a $0,2 \mathrm{~m}\left(\mathrm{pH}=5,2 ; \mathrm{V}=62 \% ; \mathrm{CTC}=42 \mathrm{mmol}_{\mathrm{c}} \mathrm{dm}^{-3}\right.$; $\mathrm{K}_{\text {resina }}=0,7 \mathrm{mmol}_{\mathrm{c}} \mathrm{dm}^{-3}$ e $\mathrm{P}_{\text {resina }}=15 \mathrm{mg} \mathrm{dm}^{-3}$ ). Foi realizada também a adubação foliar de complementação, composta pelos micronutrientes $\mathrm{B}$ e $\mathrm{Cu}$, sendo ainda utilizado $\mathrm{Zn}$ (sulfato de zinco) no experimento com Mn e Mn (sulfato manganoso) no experimento com $\mathrm{Zn}$.

Foram coletadas amostras de solo, na camada de 0 a $20 \mathrm{~cm}$, na projeção da copa, antes da aplicação dos tratamentos e no final do experimento, para avaliar o teor de micronutrientes, principalmente $\mathrm{Zn}$ e Mn, presentes no solo, durante a realização do experimento (Tabela 1).

Os dados de precipitação e temperaturas máxima, mínima e média do município de Botucatu, SP, durante o período do experimento, de agosto de 2004 a janeiro de 2005, foram obtidos do Centro integrado de informações agrometeorológicas do Estado de São Paulo (CIIAGRO, 2005) e estão apresentados na Figura 1. A primeira chuva na área experimental, após a aplicação dos tratamentos, somente ocorreu 23 dias após a pulverização.

Os resultados da concentração foliar de $\mathrm{Zn}$ e Mn foram submetidos à análise de variância segundo o teste $\mathrm{F}$ e quando significativo a $5 \%$, as médias foram comparadas segundo o teste de Tukey a 5\%, utilizando o programa Sis Var ver 4.2 (FERREIRA, 2000).

Tabela 1 - Teor de micronutrientes no solo, no início e final do experimento, média de dez amostras coletadas na área experimental, na camada de 0 a 0,2 m (Botucatu, SP, 2004/2005)

\begin{tabular}{|c|c|c|c|c|c|}
\hline \multirow{3}{*}{ Data de coleta } & \multicolumn{5}{|c|}{ Teor de micronutrientes no solo } \\
\hline & $\mathrm{B}$ & $\mathrm{Cu}$ & $\mathrm{Fe}$ & Mn & $\mathrm{Zn}$ \\
\hline & 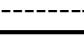 & ---- & -mg & ---- & 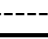 \\
\hline Agosto/04 & 0,35 & 2,9 & 55 & 5,3 & 3,9 \\
\hline Fevereiro/05 & 0,19 & 3,1 & 41 & 4,5 & 3,7 \\
\hline
\end{tabular}

Extratores: B (água quente) e Cu, Fe, Mn e Zn (DTPA a pH 7) 
Figura 1 - Precipitação e temperaturas máxima, mínima e média do município de Botucatu, SP durante o período experimental (agosto de 2004 a janeiro de 2005)

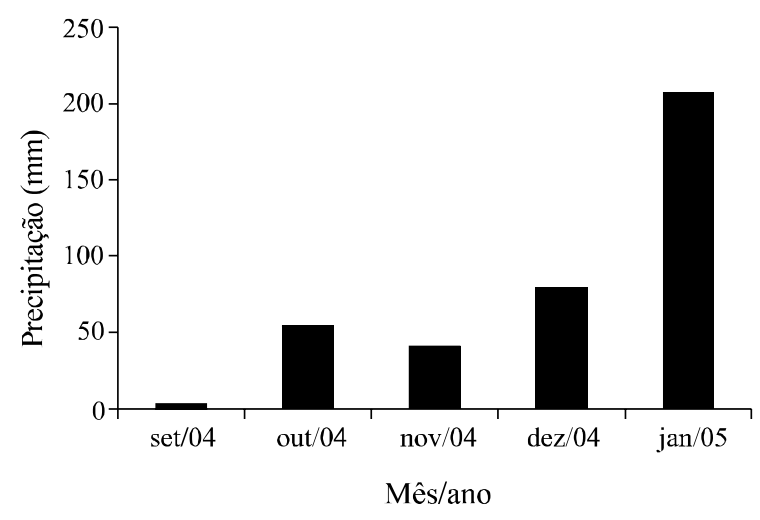

\section{RESULTADOS E DISCUSSÃO}

Antes da aplicação dos tratamentos, em setembro de 2004, época de florescimento, a concentração foliar de $\mathrm{Zn}$ e $\mathrm{Mn}$, nas laranjeiras, foi de 33 e $37 \mathrm{mg} \mathrm{kg}^{-1}$, respectivamente (Tabelas 2 e 3), estando o $\mathrm{Zn}$ em condição de deficiência ( $\mathrm{Zn}$ - 35 a $50 \mathrm{~g} \mathrm{~kg}^{-1}$ ) e o $\mathrm{Mn}$ dentro da faixa de concentração considerada adequada (Mn - 35 a $50 \mathrm{~g} \mathrm{~kg}^{-1}$ ) segundo Quaggio et al. (2005), para a época de frutificação, com frutos de 0,5 a $1,0 \mathrm{~cm}$ de diâmetro.

Em outubro de 2004, aos 30 dias após a aplicação dos tratamentos (DAT), época em que as plantas apresentavam frutos de 1 a $2 \mathrm{~cm}$, as plantas do tratamento controle apresentaram concentração de $18 \mathrm{mg} \mathrm{kg}^{-1} \mathrm{Zn}$ e $29 \mathrm{mg} \mathrm{kg}^{-1} \mathrm{Mn}$ (Tabelas 2 e 3). Mesmo apresentando alto teor inicial de $\mathrm{Zn}$ e $\mathrm{Mn}$ no solo

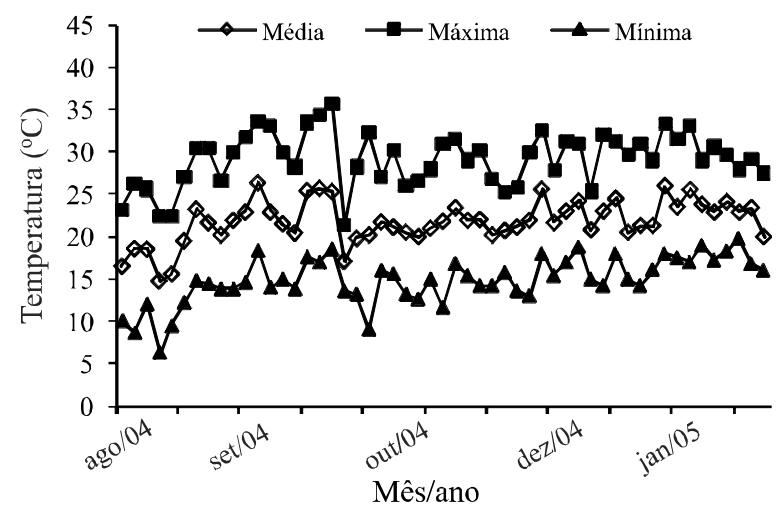

(Tabela 1), as concentrações destes micronutrientes na folha indicaram condição de deficiência segundo Quaggio et al. (2005), e, em estado fisiológico de alta demanda de nutrientes (HAAG et al., 1993), indicando a necessidade de adubação para correção.

\section{Concentração de zinco nas folhas}

A maior concentração de $\mathrm{Zn}$ nas folhas foi proporcionada pela adubação foliar com o óxido de zinco B na dose de $750 \mathrm{~g} \mathrm{ha}^{-1} \mathrm{Zn}$, apresentando incremento de $184 \%$ na concentração foliar (Figura 2). Somente as plantas do tratamento controle e as tratadas com o óxido de zinco A na dose de $375 \mathrm{~g} \mathrm{ha}^{-1} \mathrm{Zn}$, não apresentaram aumento da concentração de $\mathrm{Zn}$ em relação à concentração determinada em setembro (antes da aplicação). Santos et al. (1999), utilizando sulfatos e cloretos de $\mathrm{Zn}$ e Mn, e Tariq et al. (2007) utilizando sulfato de Zn e

Tabela 2 - Concentração de zinco em amostras foliares de laranjeira Pêra em função da data de coleta, do produto e da dose aplicada via foliar (Botucatu, SP, 2004/2005)

\begin{tabular}{lcccccc}
\hline \multirow{2}{*}{ Tratamento (fonte) } & \multirow{2}{*}{ Dose de Zn } & \multicolumn{5}{c}{ Data de coleta das amostras } \\
\cline { 2 - 7 } & & set/04 & out/04 & nov/04 & dez/04 & jan/05 \\
\cline { 2 - 7 } & 375 & 33 & $31 \mathrm{~cd}$ & $19 \mathrm{~cd}$ & $26 \mathrm{de}$ & $24 \mathrm{c}$ \\
\hline ZnO A & 750 & 33 & $57 \mathrm{~b}$ & $26 \mathrm{~cd}$ & $33 \mathrm{~cd}$ & $28 \mathrm{bc}$ \\
ZnO A & 375 & 33 & $47 \mathrm{bc}$ & $28 \mathrm{c}$ & $32 \mathrm{cde}$ & $31 \mathrm{abc}$ \\
ZnO B & 750 & 33 & $94 \mathrm{a}$ & $56 \mathrm{a}$ & $49 \mathrm{a}$ & $39 \mathrm{a}$ \\
ZnO B & 375 & 33 & $49 \mathrm{bc}$ & $28 \mathrm{c}$ & $37 \mathrm{bc}$ & $35 \mathrm{abc}$ \\
ZnSO4 & 750 & 33 & $65 \mathrm{~b}$ & $41 \mathrm{~b}$ & $41 \mathrm{~b}$ & $37 \mathrm{ab}$ \\
ZnSO4 & --- & 33 & $18 \mathrm{~d}$ & $15 \mathrm{~d}$ & $24 \mathrm{e}$ & $41 \mathrm{a}$ \\
controle & --- & ---- & 18,43 & 15,33 & 10,01 & 13,78 \\
CV $(\%)$ & & & & &
\end{tabular}

Média seguidas da mesma letra nas colunas não diferem entre si pelo teste de Tukey à $5 \%$ 
Tabela 3 - Concentração de manganês em amostras foliares de laranjeira Pêra em função da data de coleta, do produto comercial e da dose aplicada via foliar (Botucatu, SP, 2004/2005)

\begin{tabular}{|c|c|c|c|c|c|c|}
\hline \multirow{3}{*}{ Tratamento (fonte) } & \multirow{2}{*}{ Dose de $\mathrm{Mn}$} & \multicolumn{5}{|c|}{ Data de coleta das amostras } \\
\hline & & set/04 & out/04 & nov/04 & $\operatorname{dez} / 04$ & jan/05 \\
\hline & $\mathrm{g} \mathrm{ha}^{-1}$ & --------------- & --------- & $\mathrm{kg}^{-1}--$ & ------ & --------------- \\
\hline $\mathrm{MnCO} 3 \mathrm{~A}$ & 250 & 37 & $37 \mathrm{c}$ & $50 \mathrm{ab}$ & 38 & 53 \\
\hline $\mathrm{MnCO} 3 \mathrm{~A}$ & 500 & 37 & $50 \mathrm{~b}$ & $48 \mathrm{ab}$ & 39 & 54 \\
\hline $\mathrm{MnCO} 3 \mathrm{~B}$ & 250 & 37 & $54 \mathrm{~b}$ & $56 \mathrm{ab}$ & 41 & 52 \\
\hline $\mathrm{MnCO} 3 \mathrm{~B}$ & 500 & 37 & $71 \mathrm{a}$ & $63 \mathrm{a}$ & 46 & 54 \\
\hline $\mathrm{MnSO} 4$ & 250 & 37 & $50 \mathrm{~b}$ & $56 \mathrm{ab}$ & 44 & 56 \\
\hline $\mathrm{MnSO} 4$ & 500 & 37 & $59 \mathrm{ab}$ & $58 \mathrm{ab}$ & 45 & 59 \\
\hline Controle & --- & 37 & $29 \mathrm{c}$ & $43 \mathrm{~b}$ & 38 & 47 \\
\hline $\mathrm{CV}(\%)$ & --- & --- & 10,00 & 12,97 & 10,19 & 12,16 \\
\hline
\end{tabular}

Média seguidas da mesma letra nas colunas não diferem entre si pelo teste de Tukey à $5 \%$

Figura 2 - Alteração (aumento ou redução) da concentração de $\mathrm{Zn}$ nas folhas de laranjeira Pêra em função da data de coleta, do produto e da dose aplicada via foliar (Botucatu, SP, 2004/2005)

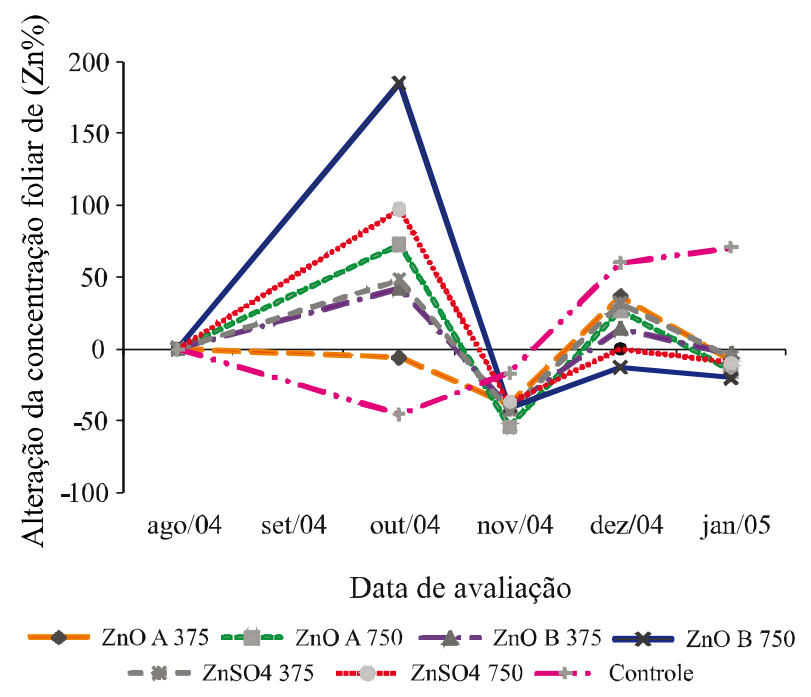

sulfato de Mn, também observaram que aplicação foliar de micronutrientes favoreceu a absorção e resultou no aumento do teor foliar de $\mathrm{Mn}$ e $\mathrm{Zn}$ em folhas de laranjeira, 30 dias após a aplicação. A maior capacidade do óxido de Zn B em elevar à concentração foliar de Zn em relação ao A deve estar ligada à presença da ureia $\left(18 \mathrm{~g} \mathrm{~L}^{-1} \mathrm{~N}\right)$ no primeiro, pois ambos apresentam mesmo princípio, insolúveis em água, densidade e $\mathrm{pH}$ semelhantes, diferindo, principalmente no tamanho das partículas, que neste caso, no entanto, são menores no óxido de $\mathrm{Zn}$ A. Partículas menores podem ser mais facilmente absorvidas pelas folhas através de poros existentes na cutícula, chamados de ectodesmatas, com diâmetro menor que $1 \mathrm{~nm}(0,001 \mu \mathrm{m})$, como é o caso da ureia (raio molecular de 0,264 nm) (WÓJCIK, 2004).

Houve redução da concentração foliar de $\mathrm{Zn}$ de $6,1 \%$ para as plantas submetidas ao óxido de zinco A, na menor dose, e de $45,5 \%$ no tratamento controle em relação à concentração de Zn, antes da adubação foliar (Figura 2). Assim, os resultados do tratamento controle evidenciaram que o $\mathrm{Zn}$ disponível no solo (Tabela 1), praticamente não foi utilizado pelas plantas, provavelmente, devido à falta de chuva em setembro de 2004 (Figura 1).

Aos 60 DAT, a maior concentração de $\mathrm{Zn}$ nas folhas foi mantida nas plantas adubadas com o óxido de zinco $\mathrm{B}$, na dose de $750 \mathrm{~g} \mathrm{ha}^{-1} \mathrm{Zn}$. As plantas tratadas com o sulfato de $\mathrm{Zn}$, também na dose de $750 \mathrm{~g} \mathrm{ha}^{-1} \mathrm{Zn}$, apresentaram a segunda maior concentração de $\mathrm{Zn}$ na folha em relação às plantas dos demais tratamentos (Tabela 2). Somente as plantas que receberam estes dois tratamentos não necessitariam de uma segunda aplicação foliar de $\mathrm{Zn}$, pois a concentração deste nas folhas, reduziu, de outubro para novembro, ficando abaixo do nível mínimo adequado $\left(35 \mathrm{mg} \mathrm{kg}^{-1}\right)$ nas plantas dos demais tratamentos. $\mathrm{O}$ óxido de zinco, por ser uma fonte com o nutriente insolúvel, tende a ter um efeito mais prolongado na concentração foliar de $\mathrm{Zn}$ do que o sulfato. De acordo com Boaretto et al. (2003) menos de $10 \%$ das quantidades de Zn e Mn que são depositadas na superfície das folhas de laranjeira são absorvidas, mas são suficientes para elevar os teores dos micronutrientes das folhas que recebem a adubação foliar.

Esperava-se, aos 90 DAT, que também ocorresse redução na concentração foliar de $\mathrm{Zn}$, evidenciando a necessidade de uma segunda aplicação de $\mathrm{Zn}$ via foliar, como verificado aos 60 DAT. No entanto, houve aumento da concentração de $\mathrm{Zn}$ nas folhas de todas as plantas com exceção das que apresentavam as maiores concentrações 
em novembro (Tabela 2 e Figura 2). Provavelmente, este efeito ocorreu devido ao aumento das chuvas e da temperatura (Figura 1), à calagem e adubação realizadas em novembro que proporcionaram novo estímulo ao crescimento da planta (folhas e frutos) gerando maior absorção dos nutrientes do solo, inclusive o $\mathrm{Zn}$, cujo teor no solo estava alto em setembro de 2004 e permaneceu alto até o final do experimento, em fevereiro de 2005 (3,9 e $3,7 \mathrm{mg} \mathrm{dm}^{-3}$, respectivamente). De acordo com Quaggio et al. (2003), em experimento de adubação com boro e zinco no solo em complementação à aplicação via foliar em laranjeira Pêra, a produtividade máxima foi alcançada com 3,0 $\mathrm{mg} \mathrm{dm}^{-3}$ de $\mathrm{Zn}$ no solo na camada de 0-0,2 m, valor inferior ao teor encontrado no presente experimento. A contribuição do $\mathrm{Zn}$ do solo no teor de $\mathrm{Zn}$ na folhas de laranjeira também foi verificada por Sartori et al. (2008a).

A concentração foliar de $\mathrm{Zn}$, aos 120 DAA, foi maior nas plantas do tratamento controle e naquelas que receberam a aplicação do óxido de $\mathrm{Zn} \mathrm{B}$, na dose de $750 \mathrm{~g} \mathrm{ha}^{-1} \mathrm{Zn}$ em relação às plantas que receberam o óxido de $\mathrm{Zn} \mathrm{A}$, independente da dose. Observou-se que houve redução na concentração de Zn nas folhas de todos os tratamentos, com exceção do controle, que apresentou aumento da concentração foliar de $\mathrm{Zn}$, desde outubro até o final do experimento, ficando com a mesma concentração foliar de $\mathrm{Zn}$ que o tratamento que recebeu a maior dose do óxido de $\mathrm{Zn}$ B (Figura 2 e Tabela 2). A concentração de Zn foliar reduziu em $33 \%$, de novembro a janeiro, nas plantas do tratamento que recebeu óxido de $\mathrm{Zn} \mathrm{B}$, na maior dose (que apresentaram as maiores concentrações foliares de $\mathrm{Zn}$ em outubro). Contudo, nas plantas do tratamento controle houve aumento de $131 \%$ na concentração foliar de $\mathrm{Zn}$, no mesmo período (que apresentaram as menores concentrações deste nutriente em outubro). Este resultado demonstra que o aumento da concentração foliar de $\mathrm{Zn}$ foi maior nas plantas mais carentes em Zn, como citado por Malavolta et al. (2006) para os nutrientes em geral, no qual planta com menor concentração do nutriente tem absorção favorecida deste em relação a plantas com alta concentração.

\section{Concentração de manganês nas folhas}

Na primeira data de avaliação (30 DAT) a maior concentração de Mn nas folhas foi proporcionada pela adubação foliar com o carbonato de manganês $\mathrm{B}$ e com sulfato manganoso, ambos na dose de $500 \mathrm{~g} \mathrm{ha}^{-1} \mathrm{Mn}$, contudo, somente as concentrações de $\mathrm{Mn}$ nas plantas submetidas ao carbonato de manganês B diferiram dos demais tratamentos, pois o sulfato manganoso foi superior apenas ao controle e ao carbonato de Mn A, na menor dose. Papadakis et al. (2007) também observaram aumento da concentração foliar de Mn, em dois genótipos de citros, quando pulverizados com sulfato manganoso. Apesar do mesmo princípio (carbonato) e mesma concentração de Mn, o carbonato de Mn B foi mais eficiente em aumentar a concentração foliar de Mn do que o carbonato de Mn A, apesar de este apresentar menores partículas. Segundo Malavolta (2006) a ureia apresenta a difusão facilitada rompendo ligações de éster e de éter da cutícula, podendo abrir "caminhos" na rede lipídica podem ajudar na absorção de elementos que acompanham, como no caso do carbonato de $\mathrm{Mn} \mathrm{B}$, que possui $69 \mathrm{~g} \mathrm{~L}^{-1}$ de $\mathrm{N}$, na forma de ureia.

Com exceção do carbonato de $\mathrm{Mn} \mathrm{A}$, na dose de $250 \mathrm{~g} \mathrm{ha}^{-1} \mathrm{Mn}$, todas as demais fontes aplicadas via foliar promoveram acréscimo às concentrações foliares superando os valores constatados no tratamento controle. Todas as fontes proporcionaram aumento da concentração foliar de Mn para valores considerados adequados segundo Quaggio et al. (2005) para laranjeiras no Estado de São Paulo.

Em comparação à concentração de Mn foliar, determinada um mês antes da aplicação, houve aumento de $92 \%$, com a utilização do carbonato de manganês $\mathrm{B}$, na dose de $500 \mathrm{~g} \mathrm{ha}^{-1} \mathrm{Mn}$ (Figura 3). As menores concentrações de $\mathrm{Mn}$ foliar foram constatadas quando se utilizou o carbonato de manganês A na menor dose, o qual manteve o teor na folha, e no tratamento controle, havendo redução da concentração foliar de $\mathrm{Mn}$, em $22 \%$, em relação à concentração em agosto de 2004 (Tabela 3), corroborando com o experimento de $\mathrm{Zn}$, que apesar do teor adequado de Mn no solo, este não supre adequadamente as plantas de laranja na ausência de chuvas. Por se tratar de elemento pouco móvel, o fornecimento deste, por meio de outros órgãos mais velhos para novas folhas e flores, não é suficiente.

Sessenta dias após a aplicação dos tratamentos, época em que as plantas apresentavam frutos com 2 a $3 \mathrm{~cm}$ de diâmetro, o carbonato de manganês $B$ na dose de $500 \mathrm{~g} \mathrm{ha}^{-1} \mathrm{Mn}$, também proporcionou maior concentração de Mn na folha em relação ao controle, porém, não diferindo mais dos demais produtos aplicados, e estes não diferindo do controle. No tratamento com carbonato de manganês B houve redução de $11 \%$ na concentração foliar de $\mathrm{Mn}$ em relação à avaliação realizada em outubro (71 para $63 \mathrm{mg} \mathrm{kg}{ }^{-1}$ ), enquanto nos demais tratamentos houve um pequeno aumento na concentração de Mn (Tabela 3 e Figura 3), sendo maior no tratamento controle, apesar do teor de Mn se manter dentro da faixa adequada recomendada por Quaggio et al. (2005) para todos os tratamentos.

Aos 90 dias após a aplicação dos tratamentos (dezembro de 2004), época em que as plantas apresentavam frutos com 3 a $5 \mathrm{~cm}$ de diâmetro, houve redução na concentração de Mn em todos os tratamentos 
Figura 3 - Alteração (aumento ou redução) da concentração de Mn nas folhas de laranjeira Pêra em função da data de coleta, do produto e da dose aplicada via foliar (Botucatu, SP, 2004/2005)

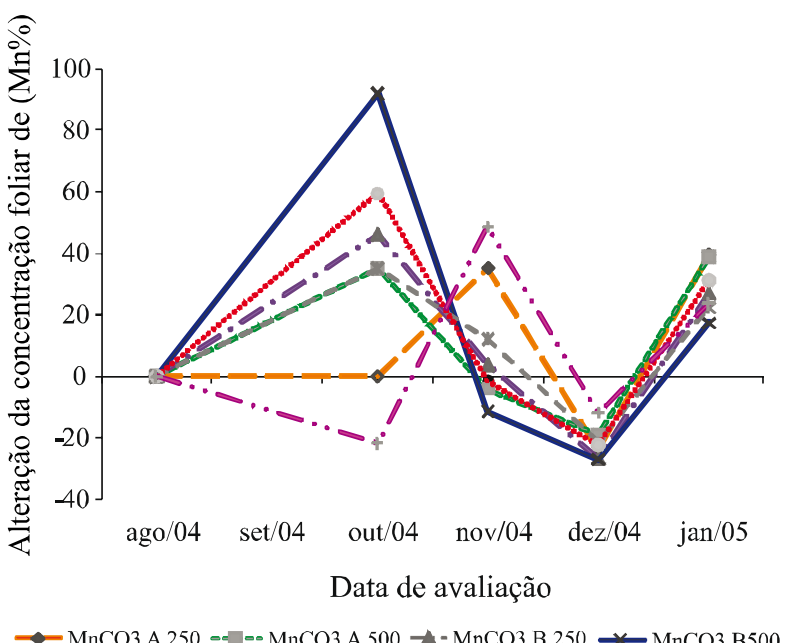

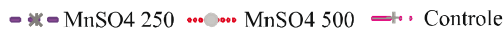

O óxido de zinco e o carbonato de manganês são produtos insolúveis em água, portanto, para que estes sejam utilizados para adubação foliar cada empresa tem que adotar uma metodologia de produção, como agentes precipitantes, tamanho de partículas, fontes e velocidade de rotação para produzir uma solução homogênea (FERREIRA, 2009). Quanto menor a partícula do composto fertilizante menor será a ocorrência de decantação e posteriores problemas de qualidade do produto final. Apesar dos carbonatos de Mn A e B e óxidos de Zn A e $\mathrm{B}$ apresentarem mesmo princípio químico e terem sido aplicados em concentrações equivalentes, houve diferenças significativas no aumento do teor foliar do $\mathrm{Mn}$ e do $\mathrm{Zn}$ em função do produto aplicado, diferença esta que pode ter sido causada pela qualidade dos mesmos (tamanho e uniformidade das partículas em suspensão concentrada, aditivos, etc.), critério que deve ser utilizado na escolha de produtos para adubação foliar. A adubação foliar pode ser positiva no processo produtivo, por outro lado, a falta de conhecimento e definição sobre técnicas e produtos mais adequados para essa prática, podem comprometer a obtenção de bons resultados (ROSSI et al., 2004) e com isso, levar a redução da sua utilização por agricultores.

\section{CONCLUSÕES}

Contudo, a concentração de Mn nas folhas das plantas de todos os tratamentos ficou dentro da faixa considerada adequada, não indicando a necessidade de uma segunda aplicação. Quaggio et al. (2003) citam que existem pesquisas demonstrando a eficiência da aplicação foliar do Zn, Mn e Fe, porém é necessário aplicá-los a cada fluxo de vegetação nova, já que os nutrientes aplicados na vegetação anterior não se redistribuem na planta. Todavia, no presente experimento verificou-se que o teor foliar de Mn se manteve adequado para todos os tratamentos a partir de novembro, com a incidência de chuva e após a calagem e a adubação com NPK. Bregonci et al. (2008) também observaram aumento no teor foliar de $\mathrm{Mn}$ e $\mathrm{Zn}$ em abacaxizeiro após a adubação com NPK. Este fato remete à necessidade do monitoramento do estado nutricional das plantas em decorrência das mudanças climáticas e do manejo da cultura (por exemplo, calagem e adubação), podendo ser descartada nova adubação foliar.

Em janeiro de 2005, 120 dias após a aplicação dos tratamentos, época em que as plantas apresentavam frutos com 3 a $7 \mathrm{~cm}$ de diâmetro, ocorreu aumento na concentração de Mn em todos os tratamentos (Tabela 3 e Figura 3), provavelmente pelo mesmo efeito discutido sobre a concentração de $\mathrm{Zn}$, no tratamento controle. No entanto, este foi mais tardio que o $\mathrm{Zn}$, provavelmente, pela condição de maior deficiência deste em relação ao Mn, no início do experimento. Além disso, as doses de $\mathrm{Mn}$ aplicadas via foliar foram menores que a de $\mathrm{Zn}$.
1. A aplicação foliar com carbonato de manganês B, na dose de $500 \mathrm{~g} \mathrm{ha}^{-1} \mathrm{Mn}$, e com óxido de zinco B, na dose de $750 \mathrm{~g} \mathrm{ha}^{-1}$, proporcionaram, respectivamente, níveis nutricionais adequados de $\mathrm{Mn}$ e $\mathrm{Zn}$ nas folhas de laranjeira.

2. Na ausência de chuvas, os teores adequados de Mn e Zn no solo, não permitem suprir satisfatoriamente as laranjeiras Pêra enxertadas em limoeiro cravo.

\section{REFERÊNCIAS}

ALCARDE, J. C.; VALE, F. Solubilidade de micronutrientes contidos em formulações de fertilizantes, em extratores químicos. Revista Brasileira de Ciência do Solo, v. 27, n. 2, p. 363-372, 2003.

BOARETTO, A. E. et al. Foliar micronutrient application effects on citrus fruit yield and on soil and foliage $\mathrm{Zn}$ concentrations and $65 \mathrm{Zn}$ mobilization within the plant. Acta Horticulturae, n. 594, p. 203-209, 2002.

BOARETTO, A. E.; MURAOKA, T.; BOARETTO, R. M. Absorção e translocação de Mn, Zn e B Aplicados via foliar em Citros. Laranja, v. 24, n. 1, p. 177-197, 2003.

BREGONCI, I. S. et al. Teor foliar de macro e micronutrientes de mudas micropropagadas de abacaxi Gold na fase de aclimatação com diferentes níveis de NPK. Revista de Ciência Agronômica, v. 39, n. 2, p. 233-239, 2008. 
CIIAGRO. Centro Integrado de Informações Agrometeorológicas. Instituto Agronômico de Campinas IAC. Disponível em: 〈http://www.ciiagro.sp.gov.br>. Acesso em: 02 out. 2005.

EMBRAPA. Sistema Brasileiro de Classificação dos Solos. Brasília:EMBRAPA, 1999. 412 p.

FAOSTAT. Food and Agriculture Organization of the United Nations. Disponível em: <http://faostat3.fao.org/home/index. html\#DOWNLOAD>. Acesso em: 03 abr. 2013.

FERREIRA, D. F. Análise estatística por meio do SISVAR (Sistema para Análise de Variância) para Windows versão 4.0. In: REUNIÃO ANUAL DA REGIÃO BRASILEIRA DA SOCIEDADE INTERNACIONAL DE BIOMETRIA, 45., 2000, São Carlos. Anais... São Carlos: UFSCar, 2000. p. 255-258.

FERREIRA, J. M. F. Preparação de óxidos de zinco e manganês via precipitação em solução homogênea, para utilização na agricultura como adubo foliar. 2009. 123f. Dissertação (Mestrado em Engenharia Química) Universidade de São Paulo, Lorena, 2009.

GHILARDI, A. A. et al. Citricultura paulista: exigência física de fatores de produção, estimativa de custo e evolução das técnicas agrícolas. Informações Econômicas, v. 32, n. 9, p. 21-45, 2002.

HAAG, H. P. et al. Variação de matéria seca e de nutrientes nas folhas e nos frutos, produção de ácido ascórbico e suco, em seis cultivares de citros, durante um ciclo. Scientia Agricola, v. 50, n. 2, p. 193-203, 1993.

IBGE. Instituto Brasileiro de Geografia e Estatística. Indicadores IBGE. Disponível em: < http://www.ibge. gov.br/home/estatistica/indicadores/agropecuaria/lspa/ estProdAgr_201203.pdf>. Acesso em: 03 abr. 2013.

MALAVOLTA, E.; VITTI, G. C.; OLIVEIRA, S. A. Avaliação do estado nutricional das plantas; princípios e aplicações. 2.ed. Piracicaba: Associação Brasileira para Pesquisa da Potassa e do Fosfato, 1997. 201p.

MALAVOLTA, E. Manual de nutrição mineral de plantas. São Paulo: Editora Ceres. 2006. 638p.

MIRANDA, R. S. et al. Deficiência nutricional em plântulas de feijão-de-corda decorrente da omissão de macro e micronutrientes. Revista Ciência Agronômica, v. 41, n. 3, p. 326-333, 2010.
PAPADAKIS,I. E.; SOTIROPOULOS, T. E.; THERIOS, I. N. Mobility of Iron and Manganese within Two Citrus Genotypes after Foliar Applications of Iron Sulfate and Manganese Sulfate Journal of Plant Nutrition, v. 30, p. 1385-1396, 2007.

QUAGGIO, J. A. et al. Fertilização com boro e zinco no solo em complementação à aplicação via foliar em laranjeira 'Pêra' . Pesquisa Agropecuária Brasileira, v. 38, n. 5, 2003.

QUAGgio, J. A.; MATTOS JUNIOR, D.; CANTARELLA, H. Manejo da fertilidade dos olo na citricultura. In: MATTOS JUNIOR, D.; DENEGRI, J.D.; PIO, R.M.; POMPEU JUNIOR, J. (Ed.). Citros. Campinas, Sp: Instituto Agronômico, 2005. p..483-517.

ROSSI, R. M.; NEVES, M. F.; CARVALHO, D. T. Características do processo de decisão de compra pelos citricultores paulistas em relação a fertilizantes foliares. Laranja, v. 25, n. 1, p. 19-35, 2004.

RUSCHEL, J. et al. Concentrações foliares do porta-enxerto limoeiro 'cravo' em função da adubação N, P, K, Ca e S. Scientia Agricola, v. 61, n. 5, p. 501-506, 2004.

SANTOS, C. H. et al. Adubos foliares quelatizados e sais na absorção de boro, manganês e zinco em laranjeira Pêra. Scientia Agricola, v. 56, n. 4, p. 999-1004, 1999.

SARTORI, R. H. et al. Absorção radicular e foliar de ${ }^{65} \mathrm{Zn}$ e sua redistribuição em laranjeiras. Revista Brasileira de Fruticultura, v. 30, n. 2, p. 523-527, 2008a .

SARTORI, R. H. et al. Redistribuição do zinco em laranjeiras. Laranja, v. 29, n. 1-2, p.87-97, 2008b.

TARIQ, M. et al. Effect of foliar application of micronutrients on the yield and quality of sweet orange (Citrus sinensis L.). Pakistan Journal of Botanical, v. 10, n. 11, p. 1823-1888, 2007.

WÓJCIK, P. Uptake of mineral nutrients from foliar fertilization. Journal of Fruit and Ornamental Plant Research, v. 12, p. 201-218, 2004. (Special Edition)

YASEEN, M.; AHMAD M. Nutrition management in citrus: effect of multinutrients foliar feeding on the yield of kinnow at different locations. Pakistan Journal of Botanical, v. 42, n. 3, p. 1863-1870, 2010. 